Louisiana State University

LSU Digital Commons

$1-16-2009$

\title{
Flow cytometric and immunohistochemical detection of in vivo BrdU-labeled cells in mouse fat depots
}

\author{
Jaroslaw Staszkiewicz \\ Pennington Biomedical Research Center \\ Jeffrey Gimble \\ Pennington Biomedical Research Center \\ Courtney Cain \\ Pennington Biomedical Research Center \\ Marilyn Dietrich \\ School of Veterinary Medicine \\ David Burk \\ Pennington Biomedical Research Center
}

See next page for additional authors

Follow this and additional works at: https://digitalcommons.Isu.edu/biosci_pubs

\section{Recommended Citation}

Staszkiewicz, J., Gimble, J., Cain, C., Dietrich, M., Burk, D., Kirk-Ballard, H., \& Gawronska-Kozak, B. (2009). Flow cytometric and immunohistochemical detection of in vivo BrdU-labeled cells in mouse fat depots. Biochemical and Biophysical Research Communications, 378 (3), 539-544. https://doi.org/10.1016/ j.bbrc.2008.11.092

This Article is brought to you for free and open access by the Department of Biological Sciences at LSU Digital Commons. It has been accepted for inclusion in Faculty Publications by an authorized administrator of LSU Digital Commons. For more information, please contact ir@lsu.edu. 


\section{Authors}

Jaroslaw Staszkiewicz, Jeffrey Gimble, Courtney Cain, Marilyn Dietrich, David Burk, Heather Kirk-Ballard, and Barbara Gawronska-Kozak 


\title{
Flow cytometric and immunohistochemical detection of in vivo BrdU-labeled cells in mouse fat depots
}

\author{
Jaroslaw Staszkiewicz ${ }^{a, b}$, Jeffrey Gimble ${ }^{a}$, Courtney Cain ${ }^{a}$, Marilyn Dietrich $^{c}$, David Burk $^{a}$, \\ Heather Kirk-Ballard ${ }^{\mathrm{a}}$, and Barbara Gawronska-Kozak ${ }^{\mathrm{a}}{ }^{*}$ \\ a Pennington Biomedical Research Center, Louisiana State University System, 6400 Perkins Rd., \\ Baton Rouge, LA 70808, USA ${ }^{b}$ Department of Animal Physiology, Warmia \& Mazury University, \\ Olsztyn, Poland ${ }^{c}$ LSU Flow Cytometry Facility, School of Veterinary Medicine, Louisiana State \\ University, Baton Rouge, LA, USA
}

\begin{abstract}
This study has determined the natural frequency and localization of progenitor/stem cells within fat depots in situ based on their ability to retain DNA nucleotide label (BrdU). Neonate and mature male C57BL6/J mice were injected intraperitoneally with BrdU- and label-retaining cells (LRC) were quantified in fat depots by immunohistochemical, immunofluorescent, and flow cytometric methods. In neonates, LRC constituted $27 \%$ of the cells in inguinal fat (iWAT) and $65 \%$ in interscapular brown fat (BAT) after Day 10 and 26\% of the cells in epididymal fat (eWAT) after Day 28. After 52 days, the LRC accounted for $0.72 \%$ of iWAT, $0.53 \%$ of eWAT and $1.05 \%$ of BAT, respectively. The BrdU-labeled cells localized to two areas: single cells distributed among adipocytes or those adjacent to the blood vessels wall. In mature C57BL6/J mice, flow cytometric analysis determined that a majority of the LRC were also positive for stem cell antigen-1 (Sca-1).
\end{abstract}

\section{Keywords}

Label-retaining cells; BrdU; Flow cytometry; Sca-1; WAT; BAT; Adipocytes

Weight gain associated with obesity is characterized by an increase in adipose mass that is achieved by two processes: hypertrophy of existing fat cells and hyperplasia throughout generation of new adipocytes from the pool of tissue resident stem cells. Hypertrophy of adipocytes through a positive energy balance has been well documented in humans and animal models [1]. While some studies have suggested that WAT expansion during adulthood also results from an increased number of adipocytes [2,3], other studies point out that the number of fat cells stays constant in both lean and obese adults as recently shown for human adipose tissues [4]. A platform where this controversy meets is in vitro vs. in vivo studies. The tremendous progress in in vitro techniques allows for the isolation and culture of stem cells/ progenitor cells from adult tissues and the ability of adult stem cells to differentiate into several lineages, to display clonogenic potentials, and to express transcriptional factors related to their undifferentiated/pluripotent stage has been well documented [5-8]. Although many features of the molecular properties of these adult stem cells have been described, a well-defined signature for their presence is still missing [1].

(C) 2008 Elsevier Inc. All rights reserved.

* Corresponding author. Fax: +1 225763 0273. KozakB @pbrc.edu (B. Gawronska-Kozak). URL: http://www.pbrc.edu (B. GawronskaKozak).. 
The lack of precise molecular markers for adult stem cells is a limiting factor of in vivo studies and in vivo methodologies that aim to overcome this obstacle are based on the slow-cell cycling feature of stem cells [9-14]. The principle of the method posits that in vivo labeling through incorporation of $\left[{ }^{3} \mathrm{H}\right]$ thymidine or 5-bromo-2'-deoxyuridine (BrdU) into cells' DNA during the early postnatal development allows for the detection of slow-cycling/stem cells through the retention of the label in adult animals. This approach has been successfully used to identify label-retaining cells (LRC)/stem cells in epithelial compartment as in skin [12], bladder [10], colon [14], and endometrium [11], and in some of the mesenchymal compartments: myometrium [13] and kidney [9].

Adipose tissues contain a population of adult/somatic stem cells that have been isolated from human and animals $[5,15]$. These cells, termed adipose-derived stem or stromal cells (ASC), are self renewing and can differentiate along several mesenchymal tissues lineages including adipocytes, osteoblasts, myocytes, chondrocytes, endothelial cells, and neurocytes. Whereas ASC are very well characterized in vitro, there is little knowledge of their natural distribution and localization within fat tissues in vivo. Elegant studies performed by Hirsh and co-workers in the 1970s and early $1980[2,16]$ detected a small population of cells residing in the stromalvascular fraction of adipose tissues that can take up $\left[{ }^{3} \mathrm{H}\right]$ thymidine. The authors concluded that these cells "may be an adipocyte progenitor or may have some other unknown function" [16]. Following in the footsteps of Hirsh's studies, the current article describes the in vivo localization and characteristics of LRC in adipose tissues. We demonstrate the existence of LRC/stem cells in fat depots that are localized to two compartments: those close to the blood vessels wall and those sparsely distributed among adipocytes. Moreover, we show that BrdUretaining cells are stem cell antigen-1 (Sca-1) positive and hematopoietic lineage (CD45/CD4) negative. These findings confirm and extend our previous studies showing that Sca-1 is a biomarker for ear mesenchymal stem cells (EMSC) with adipogenic potential [17].

\section{Materials and methods}

\section{Experimental animals and BrdU labeling}

All experiments involving animals were approved by the Pennington Biomedical Research Center Institutional Animal Care and Use Committee in accordance with NIH guidelines. We used the BrdU labeling approach to label and then identify/quantify LRC in fat depots. In the first experiment neonate, 3.5-day-old male C57BL/6J mice $(n=10)$ were injected intraperitoneally with BrdU at a concentration of $50 \mu \mathrm{g} / \mathrm{g}$ of body weight (Sigma Co., St. Louis, MO) twice daily, at $7.00 \mathrm{am}$ and $6.00 \mathrm{pm}$ for 3 consecutive days (total 7 injections). Control animals (littermates; $n=5$ ) were injected with saline. Chase periods for BrdU-labeled fat tissues were 10, 28 or 39, and 52 days. Tissues were harvested and analyzed for BrdU containing nuclei by immunohistochemistry and immunofluorescence.

The second experiment was performed on adult animals and involved the flow cytometric detection of BrdU-retaining cells in the stromal-vascular fraction of fat depots and in bone marrow (BM) cells. Male 4-month-old C57BL/6J mice were intraperitoneally injected with $\operatorname{BrdU}(n=6)$ or saline (control $n=4)$. The BrdU dose and schedule of injections were the same as in the first experiment. Animals were euthanized $24 \mathrm{~h}(n=6)$ after the last injection of BrdU. Epididymal and inguinal fat depots were collected, minced, and digested with collagenase class I ( $2 \mathrm{mg} / \mathrm{ml}$; Worthington Biochemical Corp., Freehold, NJ). Bone marrow cells were collected from tibia and femurs. Cells were suspended in red blood cell lysing buffer (Sigma Co., St. Louis, MO) to remove erythrocyte contamination before analyzing by flow cytometry. 


\section{Histological detection of BrdU-labeled cells}

Euthanized animals were perfused with PBS via cardiac puncture followed by $4 \%$ paraformaldehyde. Dissected fat depots were embedded in paraffin and sectioned at $5 \mu \mathrm{m}$.

\section{Immunohistochemistry}

To denaturate DNA dewaxed sections were treated with $1 \mathrm{~N} \mathrm{HCl}$ at room temperature for 10 min, then with $2 \mathrm{~N} \mathrm{HCl}$ at $37^{\circ} \mathrm{C}$ for 20 min followed by incubation in $0.1 \mathrm{M}$ borate buffer. Primary anti-BrdU antibody (rat anti-mouse ab6326 Abcam) at a concentration of 1:400 was applied overnight at $4{ }^{\circ} \mathrm{C}$.

For immunohistological antibody binding detection $\mathrm{ABC}$ complex was applied (Vectastain ABC kit, Vector Laboratories, Inc., Burlingame, CA). Two types of controls were performed: (a) the primary antibody was substituted with non-specific immunoglobulin $\mathrm{G}(\mathrm{IgG})$ during the procedure, and (b) fat depot sections from saline treated animals were subjected to BrdU detection. Samples were counterstained with hematoxylin. Sections were visualized with a Zeiss microscope (Axioskop 40) using Plan-Neofluor 10× objective and photographed with a Kodak digital camera (DC290 Zoom). Quantitative analyses of immunopositive cells were made using Metamorph software. For LRC quantitation, adipocytes and BrdU-positive cells were counted from 5-fields and the label-retaining cells expressed as a percentage of total adipocytes counted. BrdU-retaining cells in brown fat tissues were expressed as a percentage of total nuclei counted.

For immunofluorescence detection of BrdU-labeled cells goat anti-rat antibodies conjugated to Alexa Fluor 488 (Molecular Probes, Eugene, OR) followed overnight incubation with primary anti-BrdU antibody were applied. BrdU expression was imaged using an Everest imaging system (Intelligent Imaging Innovation, Inc., Denver, CO) based on a Zeiss Meta 510 confocal microscope.

\section{BrdU flow cytometry assay}

Cells from the stromal-vascular fraction of fat depots or BM were first incubated with phycoerythrin (PE) conjugated anti-Sca-1 antibodies (BD Pharmingen San Diego, CA). Similar cells suspensions were incubated with PE conjugated anti-CD45 and anti-CD4 antibodies (BD Pharmingen San Diego, CA). Next cells were fixed, treated with DNase to expose BrdU epitopes, and incubated with FITC-conjugated anti-BrdU antibodies following instruction of the manual (FITC BrdU Flow Kit BD Pharmingen San Diego, CA). The flow cytometry assay was performed using a FACScan flow cytometer (Becton Dickinson, San Jose, CA) and data were analyzed with a Macintosh G5 workstation (Apple Computer, Cupertino, CA), which contains Cellquest graphics software (Becton Dickinson, San Jose, CA) for data acquisition and analysis. Gates were always set using cells isolated from animals that received injections of saline instead of BrdU, but the samples were processed and stained alongside the experimental samples. The data were expressed as a percent of BrdU, Sca-1, and CD4/CD45 positive cells per gated cells. FACS plots and data are representative of three separate experiments.

\section{Results}

\section{BrdU-retaining cells during postnatal fat depots development}

In our first experiment, we administered BrdU to 3.5-day-old mice for a period of 3 days. The fat depots were collected at Day 10, 28 or 39, and 52. In the mouse, adipose tissue is formed post-natally; subcutaneous iWAT first appears at about 1 day of age, while the visceral white fat depots appear at about 9 days of age $[1,18]$. On the other hand, BAT development starts during late gestation with developmental reaching a peak at Day 10 after birth $[1,18]$. Therefore, 
we collected BAT and inguinal white adipose tissues (iWAT) at Day 10 of postnatal life. At Day 28, 39, and 52 we collected BAT, iWAT, and epididymal white adipose tissues (eWAT).

\section{Interscapular brown adipose tissue}

At Day 10 of development quantitative analysis of BAT histological sections revealed that $65.76 \% \pm 25.9 \%$ of total nuclei are positive for BrdU (Fig. 1A and I). To confirm that BrdU incorporation is localized to the nucleus we performed double-immunofluorescence staining using FITC-conjugated anti-BrdU antibodies together with DAPI staining (Fig. 1L). As expected, BrdU staining co-localized with DAPI stained nuclei (Fig. 1L). Immunofluorescent and immunohistochemical analyses showed that LRC were uniformly distributed through BAT (Fig. 1A and L). On Day 28 the number of BrdU-positive cells had decreased to $22.8 \% \pm 2.3 \%$ (Fig. 1B and I), although the LRC distribution and intensity of staining were similar to that on Day 10. A significant decrease in number of cells positive for BrdU was observed at Day 52 (Fig. 1C and I) when $1.05 \% \pm 0.6 \%$ of cells still retained intense staining for incorporated BrdU.

\section{Inguinal white adipose tissue}

To quantify the number of BrdU-retaining cells in white fat depots, we expressed them as a percentage of the number of adipocytes. iWAT at Day 10 contained $27.43 \% \pm 2.86 \%$ of cells that were positive for BrdU (Fig. 1D, J, and M). Further analysis of immunohistologically stained sections from Days 39 and 52 of development showed a significant decrease in BrdUretaining cells. We determined that between $1-5$ cells per field at Day $39(2.83 \% \pm 2.3 \%)$ and $0-2(0.72 \% \pm 0.62 \%)$ at Day 52 cells per field were BrdU-positive (Fig. 1E, F, and J).

\section{Epididymal white fat depot}

Analysis of epididymal fat tissues of 28-day-old animals revealed that 24 days after the final IP injection of label, $26.09 \% \pm 4.12 \%$ of adipocytes are BrdU-positive (Fig. 1G and K). However, the number of BrdU-stained cells fell to $0.53 \% \pm 1.1 \%$ at Day 52, the lowest frequency among the studied fat depots (Fig. $1 \mathrm{H}$ and $\mathrm{K}$ ).

Although we observed differences in the density and the rate of decline of BrdU-positive cells among BAT, iWAT, and eWAT, the distribution of LRC was surprisingly similar irrespective of the fat depot examined. BrdU-positive cells were found in two areas: single positive cells distributed among adipocytes and those closely adjacent to the blood vessels wall (Fig. 2). This pattern of distribution was observed regardless the time point of fat depots collection 10, 39 or 52 (Fig. 2). Fig. 2 shows sections of inguinal fat depots collected at Day 10 (Fig. 2A), 39 (Fig. 2B), and 52 (Fig. 2C) and white adipose tissues surrounded BAT at Day 52 (Fig. 2D). BrdU-positive cells located in blood vessels regions appeared to be distributed along the outer wall of blood vessels. This pattern was observed in both longitudinal (Fig. 2D) and horizontal (Fig. 2B and 2C) sections of blood vessels within fat depots.

\section{BrdU-retaining cells in adult fat depots}

Our second approach was to use flow cytometry to identify a stem cell marker in BrdU-labeled cells in stromal-vascular fractions of fat depots. We first set up gating parameters that allowed us to distinguish between BrdU-labeled and non-labeled cells in experimental animals by using cells isolated from control animals (saline treated) that were processed and stained alongside the experimental samples (Fig. 3D-F). Next, we analyzed cells collected from BrdU-treated animals considering as BrdU-positive those cells which displayed fluorescent intensity greater than $99 \%$ of that displayed by cells isolated from control animals (compare, Fig. 3A and D; B and $\mathrm{E}$; and $\mathrm{C}$ and $\mathrm{F}$ ). The analysis showed that BrdU incorporation in eWAT and iWAT fat depots was 4 and 13 (respectively) times lower than in the bone marrow (Table 1). The LRC 
represented $1.7 \%$ of the stromal-vascular fraction of iWAT and $6.04 \%$ of eWAT, respectively, whereas more than $22 \%$ of BM cells were BrdU-positive (Table 1). Simultaneously, doublelabeled flow cytometric analysis was performed to evaluate stem cell antigen-1 (Sca-1), in correlation with BrdU-labeling. A representative cytofluorometric analysis of cells doublestained with antibodies directed to Sca-1 and BrdU is shown in Fig. 3. More than half of BrdUlabeled cells of stromal-vascular fraction of iWAT $(0.915 \pm 0.05 \%$ out of $1.7 \pm 0.23 \%)$ and eWAT $(3.13 \% \pm 1.77 \%$ out of $6.04 \% \pm 1.7 \%)$ exhibit Sca- 1 expression, whereas only a small proportion $(1.68 \% \pm 0.06 \%$ out of $22.46 \% \pm 3.9 \%)$ of BM cells showed Sca-1 positivity (Table 1). Additionally, in similar cell populations we analyzed cells for the expression of hematopoietic lineage markers (CD45/CD4) and BrdU-positivity. Double staining for CD45/ CD4 and BrdU detected $1.27 \% \pm 0.43 \%$ of inguinal and $4.07 \% \pm 0.62 \%$ of epididymal cell fractions (Table 1). In contrast, of the $79.71 \% \pm 1.02 \%$ of BM CD45/CD4 positive cells, $15.53 \% \pm 2.9 \%$ expressed BrdU in their nuclei.

\section{Discussion}

Using BrdU-labeling methodology followed by immunohistochemical, immunofluorescent, and flow cytometric analyses, we demonstrate the following: (1) LRC are detected in iWAT, eWAT and BAT up to 52 days of age, (2) LRC are found in two areas-single positive cells distributed among adipocytes and those closely adjacent to the blood vessels wall, and (3) the expression of the stem cell associated surface antigen, Sca-1, co-localizes with LRC.

To our knowledge this study is the first attempt to label cells within fat tissues with BrdU at a very early postnatal life and follow the retention of the labeled cells into adulthood. The seven sequential BrdU-injections into 3-day-old animals resulted in the labeling of 27\% of iWAT, $65 \%$ of BAT (at Day 10), and 26\% (at Day 28) of eWAT cells. Studies of others showed initially higher percentages of BrdU-labeled cells in the epithelial compartment of colon-77\% [14], endometrium-72\% [11], and bladder-90\% [10]. It is possible that the difference between our studies and those of others can be attributed to the slower turnover of mesenchymal cells relative to epithelial cells as has been noted for bladder epithelial and stromal cells [10]. During the chase period of 52 days we observed a rapid reduction in the number of BrdU-labeled cells from Day 10 to Day 28 (13-fold) in iWAT and a slower decline in BAT (3-fold). However, at Day 52 all fat depots examined showed a low but clearly detectable level of LRC with the lowest observed in eWAT depot $(0.53 \%)$.

Analysis of immunohistological samples consistently showed that BrdU-cells were confine to two regions within fat tissues: the perivascular wall and sparsely arranged among adipocytes regardless of fat depot or chase time point. Localization of a major group of BrdU-labeled cells to the perivasculature is consistent with the recent studies on human fat tissues that have attempted to localize the ASC niche. Traktuev et al. demonstrated that stromal cells of subcutaneous adipose tissue with properties of ASC serve structurally and functionally as pericytes [19]. A similar study by Zannettino et al. revealed that multipotential stem cell populations within human adipose tissues are intimately associated with perivascular cells [20]. In those studies [19,20], flow cytometric methods were applied to phenotype ASC in human fat tissues. We detected two different niches of LRC/ASC in mice fat depots with immunohistochemical and immunofluorescence techniques that are standard methods for the detection and quantification of molecules of interest in adipocyte tissues [21].

In our second experiment (BrdU labeling of fat depot in adult animals) we used flow cytometry to quantify and molecularly phenotype BrdU-labeled cells. The analysis showed that $1.7 \%$ of iWAT and $6 \%$ of eWAT stromal-vascular fractions of cells are BrdU-positive. These data correlate well with morphometrically quantified $2.9 \%$ of BrdU-labeled cells in retroperitoneal fat depot collected from mature rats that were given intraperitoneal injection of BrdU [21]. 
Earlier studies that used $\left[{ }^{3} \mathrm{H}\right]$ thymidine labeling showed that populations of cells in stromalvascular fractions of adipose tissue can take up this DNA precursor suggesting the presence of proliferating cells within tissue $[2,16]$. Hirsh and co-workers in their studies of de novo production of adipocytes in adult rats used biochemical and radioautographic techniques for detection of incorporated radiolabeled thymidine into fat DNA [2]. They showed that a small population of stromal-vascular fraction of epididymal ( $0.1 \%$ of total cells) and retroperitoneal $\left(0.3 \%\right.$ of total cells) fat depots, but not fat cells incorporate $\left[{ }^{3} \mathrm{H}\right]$ thymidine after IP injection into adult rats [2]. Although not substantial, discrepancies between Hirsh's and our own data can be attributed to the distinct methods of labeling followed by different detection assays and/ or differences between species (rats vs. mouse model).

To further characterize LRC we analyzed the expression of stem cell antigen-1 (Sca-1). Sca-1 has been used as a candidate marker in the search for tissue-resident stem cells [22]. Recent studies have associated Sca-1 antigenicity with adipocyte progenitors in fat depots [23] and our recent studies suggest that Sca-1 is a biomarker for ear mesenchymal stem cells (EMSC) that have the potential to become functionally active adipocytes [17]. Present FACS analysis of BrdU-labeled stromal-vascular fraction cells revealed that more than half of iWAT and eWAT fractions are Sca-1 positive. Simultaneous analysis of LRC for markers of the hematopoietic lineage (CD45 and CD4) showed that approximately $70 \%$ of inguinal and epididymal cells are positive. We conclude that LRC in stromal-vascular fractions of fat depots include the following immunophenotypes: Sca $-1^{+} / \mathrm{CD} 45^{-} / \mathrm{CD}^{-}$; $\mathrm{Sca}-1^{+} / \mathrm{CD} 45^{+} / \mathrm{CD} 4^{+}$; and

Sca- $1^{-} / \mathrm{CD} 45^{+} / \mathrm{CD}^{+}$. Further analyses of the properties of each of these sub-populations are currently underway in our laboratory.

\section{Acknowledgment}

This work was supported by National Institutes of Health; Grant No. RO1 1 P20 RR021945 COBRE.

\section{References}

1. Gesta S, Tseng YH, Kahn CR. Developmental origin of fat: tracking obesity to its source. Cell 2007;131:242-256. [PubMed: 17956727]

2. Miller WH Jr. Faust IM, Hirsch J. Demonstration of de novo production of adipocytes in adult rats by biochemical and radioautographic techniques. J. Lipid Res 1984;25:336-347. [PubMed: 6726086]

3. Sakai T, Sakaue H, Nakamura T, Okada M, Matsuki Y, Watanabe E, Hiramatsu R, Nakayama K, Nakayama KI, Kasuga M. Skp2 controls adipocyte proliferation during the development of obesity. J. Biol. Chem 2007;282:2038-2046. [PubMed: 17082193]

4. Spalding KL, Arner E, Westermark PO, Bernard S, Buchholz BA, Bergmann O, Blomqvist L, Hoffstedt J, Naslund E, Britton T, Concha H, Hassan M, Ryden M, Frisen J, Arner P. Dynamics of fat cell turnover in humans. Nature 2008;453:783-787. [PubMed: 18454136]

5. Zuk PA, Zhu M, Mizuno H, Huang J, Futrell JW, Katz AJ, Benhaim P, Lorenz HP, Hedrick MH. Multilineage cells from human adipose tissue: implications for cell-based therapies. Tissue Eng 2001;7:211-228. [PubMed: 11304456]

6. Pittenger MF, Mackay AM, Beck SC, Jaiswal RK, Douglas R, Mosca JD, Moorman MA, Simonetti DW, Craig S, Marshak DR. Multilineage potential of adult human mesenchymal stem cells. Science 1999;284:143-147. [PubMed: 10102814]

7. Toma JG, Akhavan M, Fernandes KJ, Barnabe-Heider F, Sadikot A, Kaplan DR, Miller FD. Isolation of multipotent adult stem cells from the dermis of mammalian skin. Nat. Cell Biol 2001;3:778-784. [PubMed: 11533656]

8. Guilak F, Lott KE, Awad HA, Cao Q, Hicok KC, Fermor B, Gimble JM. Clonal analysis of the differentiation potential of human adipose-derived adult stem cells. J. Cell. Physiol 2006;206:229_ 237. [PubMed: 16021633]

9. Oliver JA, Maarouf O, Cheema FH, Martens TP, Al-Awqati Q. The renal papilla is a niche for adult kidney stem cells. J. Clin. Invest 2004;114:795-804. [PubMed: 15372103] 
10. Kurzrock EA, Lieu DK, Degraffenried LA, Chan CW, Isseroff RR. Label-retaining cells of the bladder: candidate urothelial stem cells. Am. J. Physiol. Renal Physiol 2008;294:F1415-F1421. [PubMed: 18367656]

11. Chan RW, Gargett CE. Identification of label-retaining cells in mouse endometrium. Stem Cells 2006;24:1529-1538. [PubMed: 16456137]

12. Braun KM, Niemann C, Jensen UB, Sundberg JP, Silva-Vargas V, Watt FM. Manipulation of stem cell proliferation and lineage commitment: visualisation of label-retaining cells in wholemounts of mouse epidermis. Development 2003;130:5241-5255. [PubMed: 12954714]

13. Szotek PP, Chang HL, Zhang L, Preffer F, Dombkowski D, Donahoe PK, Teixeira J. Adult mouse myometrial label-retaining cells divide in response to gonadotropin stimulation. Stem Cells 2007;25:1317-1325. [PubMed: 17289934]

14. Kim SJ, Cheung S, Hellerstein MK. Isolation of nuclei from label-retaining cells and measurement of their turnover rates in rat colon. Am. J. Physiol. Cell Physiol 2004;286:C1464-C1473. [PubMed: 14960413]

15. Gimble J, Guilak F. Adipose-derived adult stem cells: isolation, Characterization, and differentiation potential. Cytotherapy 2003;5:362-369. [PubMed: 14578098]

16. Klyde BJ, Hirsch J. Isotopic labeling of DNA in rat adipose tissue: evidence for proliferating cells associated with mature adipocytes. J. Lipid Res 1979;20:691-704. [PubMed: 490048]

17. Staszkiewicz J, Gimble J, Manuel JA, Gawronska-Kozak B. IFATS Series: stem cell antigen-1 positive ear mesenchymal stem cells (EMSC) display enhanced adipogenic potential. Stem Cells. 2008

18. Xue B, Rim JS, Hogan JC, Coulter AA, Koza RA, Kozak LP. Genetic variability affects the development of brown adipocytes in white fat but not in interscapular brown fat. J. Lipid Res 2007;48:41-51. [PubMed: 17041251]

19. Traktuev DO, Merfeld-Clauss S, Li J, Kolonin M, Arap W, Pasqualini R, Johnstone BH, March KL. A population of multipotent CD34-positive adipose stromal cells share pericyte and mesenchymal surface markers, reside in a periendothelial location, and stabilize endothelial networks. Circ. Res 2008;102:77-85. [PubMed: 17967785]

20. Zannettino AC, Paton S, Arthur A, Khor F, Itescu S, Gimble JM, Gronthos S. Multipotential human adipose-derived stromal stem cells exhibit a perivascular phenotype in vitro and in vivo. J. Cell. Physiol 2008;214:413-421. [PubMed: 17654479]

21. Himms-Hagen J, Melnyk A, Zingaretti MC, Ceresi E, Barbatelli G, Cinti S. Multilocular fat cells in WAT of CL-316243-treated rats derive directly from white adipocytes. Am. J. Physiol. Cell Physiol 2000;279:C670-C681. [PubMed: 10942717]

22. Holmes C, Stanford WL. Concise review: stem cell antigen-1: expression, Function, and enigma. Stem Cells 2007;25:1339-1347. [PubMed: 17379763]

23. Crossno JT Jr. Majka SM, Grazia T, Gill RG, Klemm DJ. Rosiglitazone promotes development of a novel adipocyte population from bone marrow-derived circulating progenitor cells. J. Clin. Invest 2006;116:3220-3228. [PubMed: 17143331] 


\section{BAT}
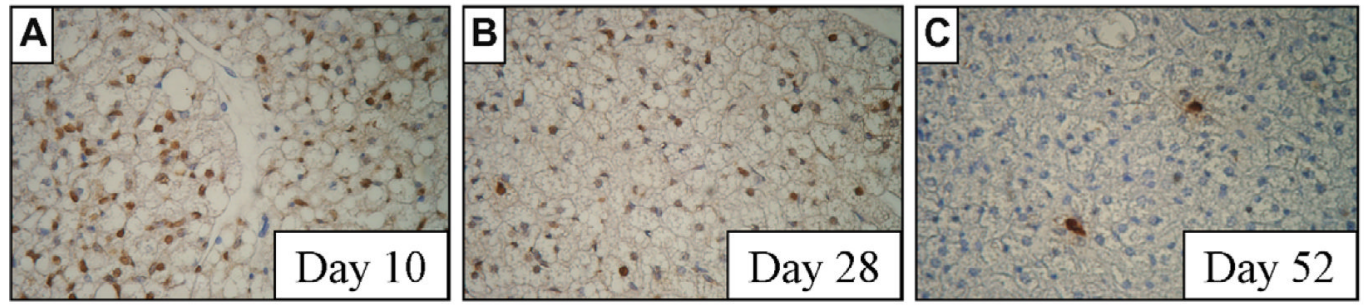

iWAT
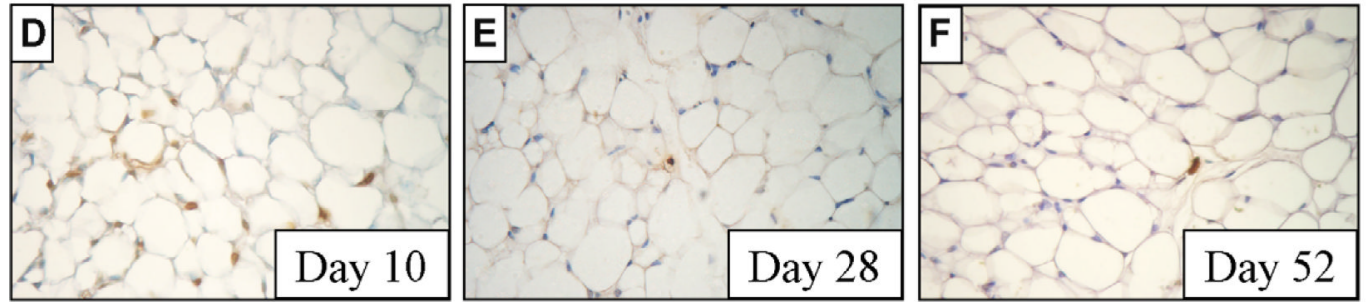

eWAT
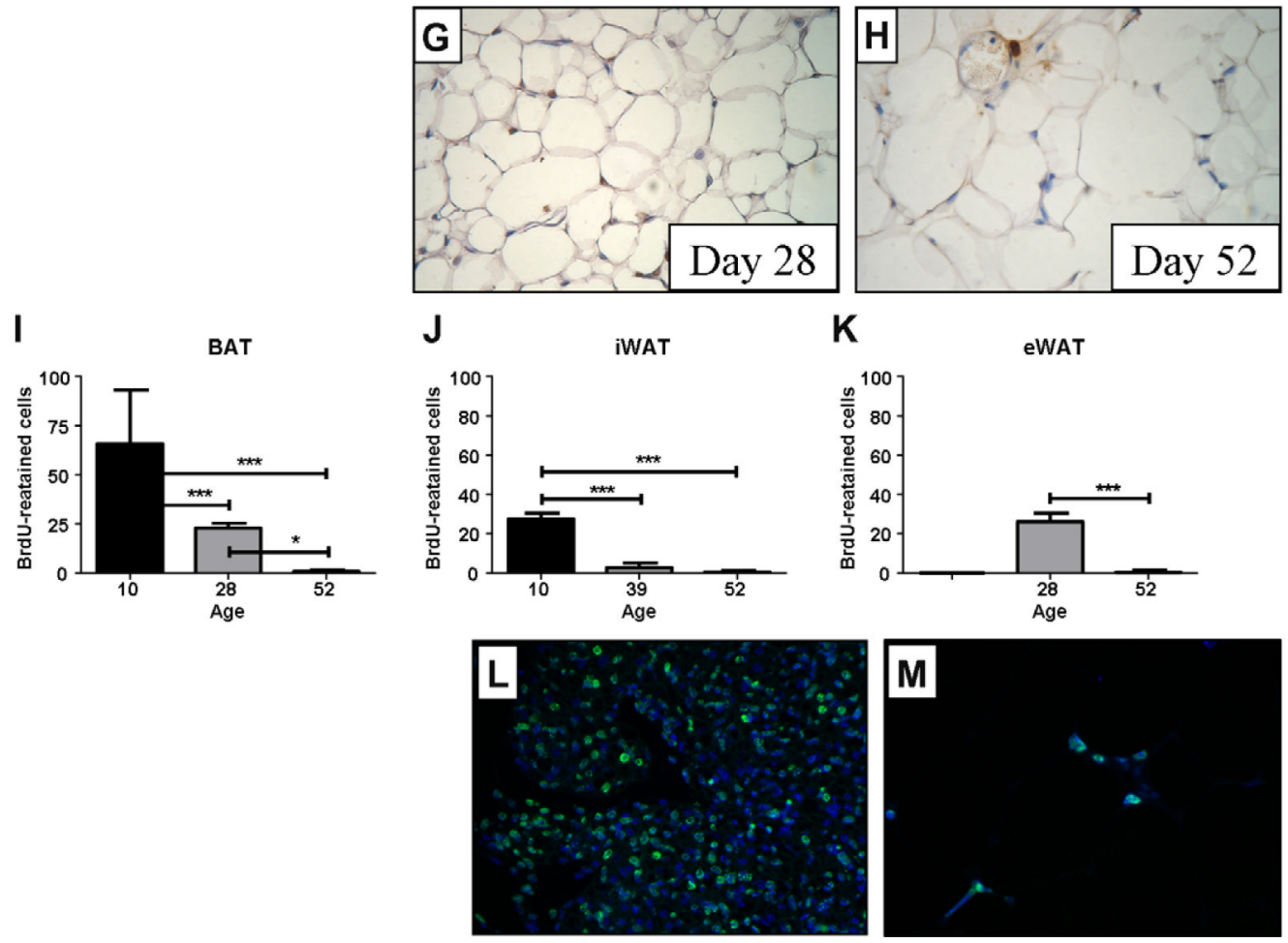

Fig. 1.

Immunohistochemical analysis of BrdU-retaining cells in mouse fat depots. 3.5-day-old male C57BL6/J mice were administered BrdU for 3 consecutive days. Animals were euthanized at different time points. BAT_Day 10 (A), Day 28 (B), Day 52 (C); iWAT_Day 10 (D), Day 39 (E), Day 52 (F); eWAT_Day 28 (G), Day 52 (H). (I-K) Mean BrdU label index. Error bars represent $\pm \mathrm{SD}(* \mathrm{p}<0.05 ; * * * \mathrm{p}<0.001)$. (L, M) Immunofluorescent detection of BrdUlabeled cells (green) in 10-day-old C57BL6/J males: (L) BAT and (M) iWAT. Cells nuclei counterstained with DAPI (blue). Magnification 20x. 

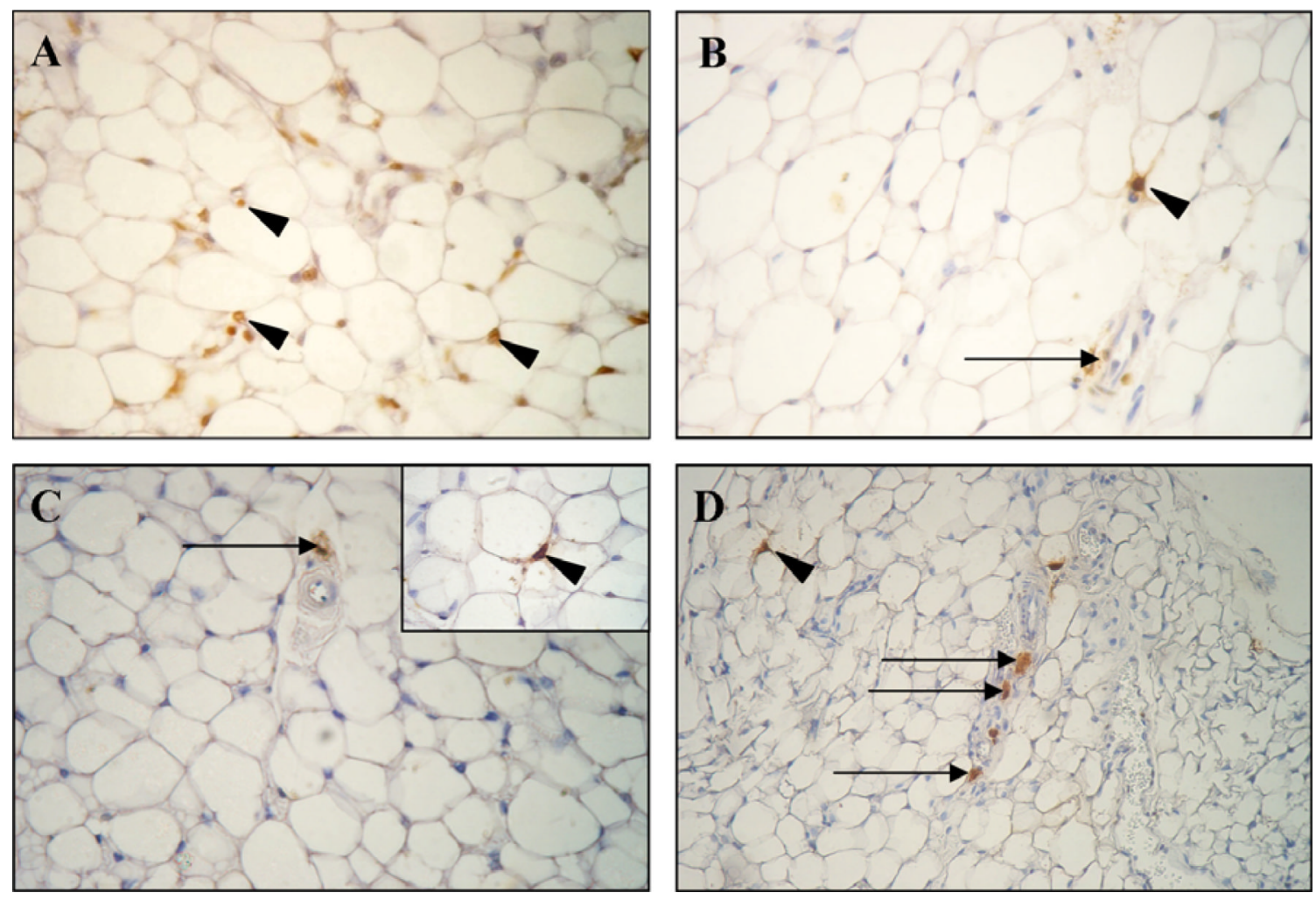

Fig. 2 .

Localization of BrdU-labeled cells within iWAT (A-C) and in white adipocyte tissues surrounding BAT (D). Immunohistochemically detected BrdU-labeled cells localize to blood vessels walls (arrows) and among adipocytes (arrowheads). Day chase period: 10 (A), 39 (B), and 52 (C, D). Magnification 20x; inset in (C) 40×. 
iWAT
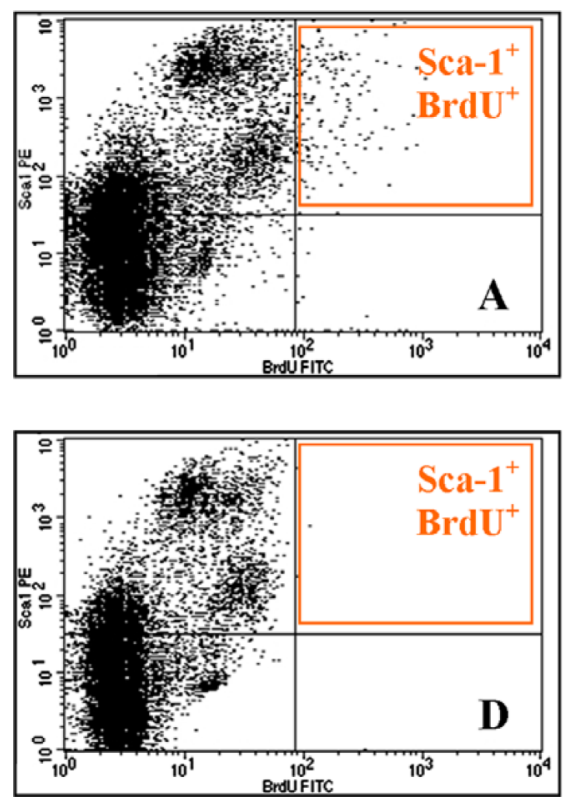

eWAT
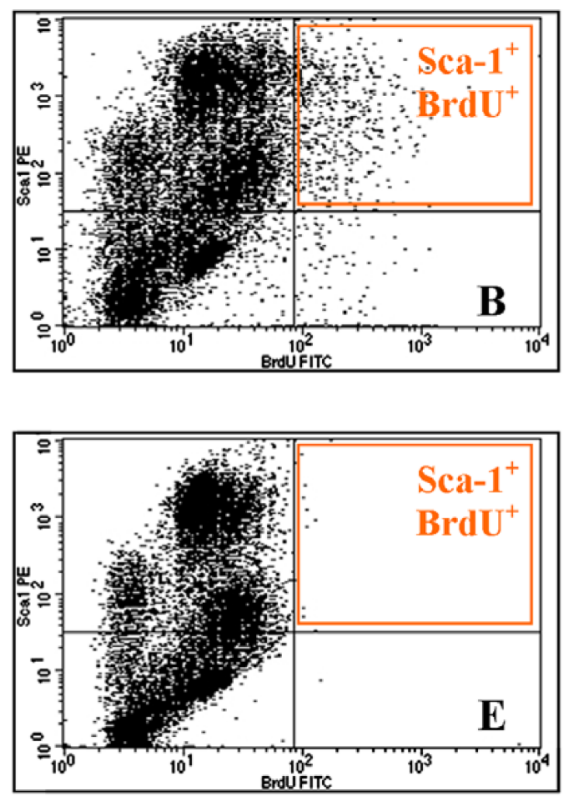

BM
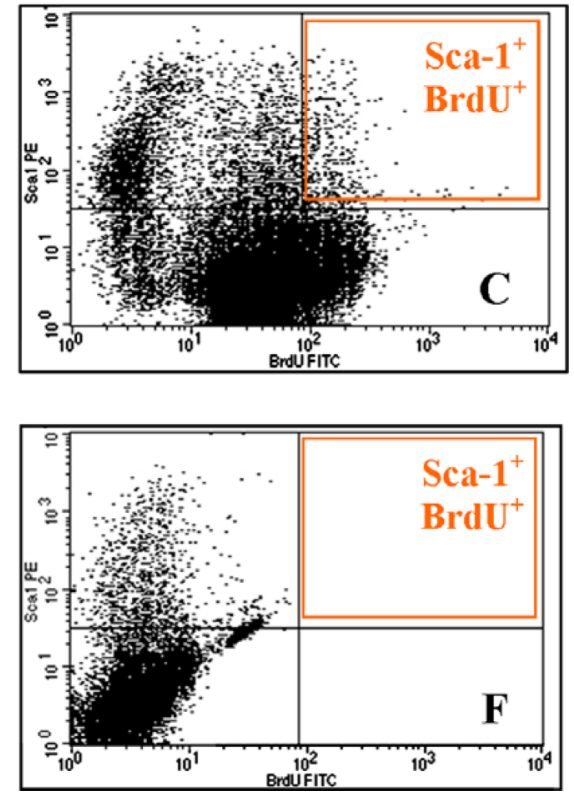

Fig. 3.

Flow cytometric analysis of BrdU retention and Sca-1 expression in stromal-vascular fraction of fat depots (A, D, B, and E) and BM (C, F) cells. (A)-(C) Representative flow cytometric analysis of iWAT (A), eWAT (B), and BM (C) collected from four months old male C57BL6/ $\mathrm{J}$ animals treated with BrdU. (D)-(F) Flow cytometry plots from control, saline treated animals (D) iWAT; (E) eWAT; and (F) BM. 
